\title{
Anterior segment biometry using ultrasound biomicroscopy and the Artemis- 2 very high frequency ultrasound scanner
}

This article was published in the following Dove Press journal:

Clinical Ophthalmology

15 January 2013

Number of times this article has been viewed

\author{
Haya M Al-Farhan \\ Reem N AIMutairi \\ King Saud University, College of \\ Applied Medical Sciences, Department \\ of Optometry and Vision Sciences, \\ Riyadh, Kingdom of Saudi Arabia
}

Purpose: To compare the precision of anterior chamber angle (ACA) and anterior chamber depth (ACD) measurements taken with ultrasound biomicroscopy (UBM) and the Artemis-2 Very High Frequency Ultrasound Scanner (VHFUS) in normal subjects.

Design: Prospective study.

Methods: We randomly selected one eye from each of 59 normal subjects in this study. Two subjects dropped out of the study; the associated data were excluded from analysis. ACA and ACD measurements were obtained using the VHFUS and the UBM. The results were compared statistically using repeated-measures analysis of variance for the intraobserver repeatability, unpaired $t$-test, and limits of agreement.

Results: The average ACA values for the UBM and the VHFUS ( \pm standard deviation) were $41.83^{\circ} \pm 5.03^{\circ}$ and $33.36^{\circ} \pm 6.03^{\circ}$, respectively. The average ACD values were $2.96 \pm 0.34 \mathrm{~mm}$ and $2.87 \pm 0.31 \mathrm{~mm}$. The intraobserver repeatability analysis of variance $P$-values for ACA and ACD measurements using UBM were 0.10 and 0.68 , respectively; for the Artemis-2 VHFUS, the respective values were 0.68 and 0.09 . The difference in ACA measurements was statistically significant $(t=8.41 ; P<0.0001)$, while the difference in ACD values was not $(t=1.51 ; P<0.13)$. The mean ACA difference was $8.50^{\circ} \pm 2.50^{\circ}$, and the limits of agreement were $+13.30^{\circ}$ to $-3.60^{\circ}$. The mean ACD difference was $0.09 \pm 0.27 \mathrm{~mm}$, and the limits of agreement ranged from $0.61 \mathrm{~mm}$ to $-0.43 \mathrm{~mm}$. The mean difference percentage of ACD was $3.1 \%$ for both instruments.

Conclusion: In case of the ACD, both instruments can be used interchangeably; however, with the ACA instruments, they cannot be used interchangeably.

Keywords: anterior chamber angle, anterior chamber depth, Artemis-2 VHF scanner, ultrasound biomicroscope, normal eyes

\section{Introduction}

Glaucoma is the second leading cause of blindness worldwide. Quigley and Broman ${ }^{1}$ estimated that by 2010, 1,440,849 and 177,869 individuals in the Middle East would have open angle glaucoma and angle closure glaucoma, respectively; the corresponding estimates for 2020 were 2,043,721 and 251,686. Several studies have reported that eyes with primary angle closure tend to share certain biometric characteristics such as shallow central anterior chamber depth (ACD), a thick lens, anterior lens position, small corneal diameter, small radius of curvature, and short axial length. ${ }^{2,3}$

The standard technique used for estimating the anterior chamber angle (ACA) width is gonioscopy; however, there are certain disadvantages with this method. The technique requires the use of minimal illumination to visualize the angle. In addition,
Correspondence: Haya M Al-Farhan Department of Optometry and Vision Sciences, College of Applied Medicine Sciences, PO Box 10219, Riyadh II433, Kingdom of Saudi Arabia Tel +96650838 II 07

Email halfarhan@ksu.edu.sa 
placing the goniolens in direct contact with the cornea may alter the angle's configuration. The interpretation of angle configuration is also dependent on the examiner's skill and experience..$^{4-7}$ More precise quantitative and objective assessment tools for the measurement of ACA and ACD will allow for more accurate predictions of the risk of angle closure. $^{6-10}$

Recently, a number of instruments have been introduced to provide precise, objective, and quantitative measurements of the anterior ocular segment. These instruments use ultrasound or optical techniques to obtain measurements. Accurate measurements of the ACA and ACD can be obtained using Visante anterior segment optical coherence tomography (AS-OCT; Carl Zeizz Meditec, Dublin, CA, USA), ${ }^{8,11-13}$ ultrasound biomicroscopy (UBM), ${ }^{11,14,15}$ Artemis-2 Very High Frequency Ultrasound Scanner (VHFUS; Scott Phillips Engineering, Victoria, Canada), ${ }^{16}$ and Orbscan $^{\circledR}$ IIz topography (Bausch and Lomb Incorporated, Rochester, NY, USA). ${ }^{14,17,18}$ The Artemis-2 VHFUS is an eye scanner that uses a probe of $50 \mathrm{MHz}$. The main advantages of the Artemis-2 VHFUS are the incorporation of an interface eye transducer and the use of saline as an acoustic coupling medium between the cornea and the probe. During scanning, the probe is moved in an arc-shaped trajectory that is matched approximately to the corneal curvature, which allows for near-normal incidence in all positions. The main disadvantage of this technique is the uncomfortable head position required of the patient. ${ }^{16,19}$

Numerous studies have compared the ACA and ACD measurements obtained using UBM with those obtained using other devices such as the OCT, Visante AS-OCT, and Orbscan ${ }^{\circledR}$ II. ${ }^{11,14,16,18,20}$ However, to the best of our knowledge, this is the first study to compare ACA and ACD measurements obtained with UBM and Artemis-2 VHFUS on normal eyes.

The aim of this study was to assess the agreement of ACA and ACD measurements obtained using the UBM and the Artemis-2 VHFUS.

\section{Subjects and methods}

Fifty-nine eyes from 59 consecutive, healthy, oculovisually normal subjects (32 men; mean age, $22 \pm 2$ years; range, 19-30 years) were enrolled in this prospective study. All subjects submitted to a comprehensive slit-lamp anterior segment examination. The exclusion criteria included a positive history (or objective signs) of ocular disease, systemic disease with ocular implications such diabetes mellitus, and an intraocular pressure $>20 \mathrm{mmHg}$. The ACA measurement is affected by the increase in crystalline lens thickness that occurs with age and/or the position of iris insertion. ${ }^{21,22}$ A change in ACA can also be induced by spherical equivalent refractive error $\geq \pm 4.00$ diopters (D) and/or corneal astigmatism $\geq-3.00 \mathrm{D}$, or corneal curvature $\geq 48 \mathrm{D} .{ }^{23} \mathrm{In}$ this study, corneal curvature was determined using an autorefractometer (Auto Kerato-Refracto-Tonometer TRK-1P; Topcon Corporation, Tokyo, Japan). One eye was randomly selected from each subject using a table of random numbers generated using Microsoft Excel (Microsoft Corporation, Redmond, WA, USA). A single investigator performed all of the ACA and ACD measurements. The ACD has been shown to increase overnight and return to baseline within 3 hours of awakening. ${ }^{24,25}$ Thus, all ACD and ACA measurements were collected during the period from 12:00 noon to 2:00 pm. Ishikawa et $\mathrm{al}^{26}$ reported that inadvertent corneal indentation during UBM can result in overestimation of the ACA. Therefore, all measurements were initially obtained using the Artemis-2 VHFUS. After an hour of rest, the same measurement was taken using the UBM. ${ }^{26}$ Three consecutive measurements were performed using each method, for each subject. All of the measurements were conducted in the same clinic, under mesopic conditions. ${ }^{27}$

Notably, two subjects dropped out of the study, as they were apprehensive about being examined with UBM. All of their associated data were excluded from the analysis. The purpose of the study was explained to all subjects, and informed consent was obtained from each subject before the examination. The study was conducted in conformance with the ethical considerations laid out in the 2008 Declaration of Helsinki, and the study protocol was approved by the research ethics review board of the College of Applied Medicine Science at King Saud University.

For the Artemis-2 VHFUS measurements, the patient sat and positioned his or her face on a three-point forehead and chin rest while placing the eye into a soft-rimmed eye-cup akin to a swimming goggle. The sterile coupling fluid filled the compartment in front of the eye, and the scanning was performed via an ultrasonically transparent (sterile) membrane, without the need for a speculum. Thus, the scanner probe did not make contact with the eye. On the Artemis-2 VHFUS, the set of three-dimensional scans used for the technique's ACA and ACD measurements required 2-3 minutes per eye. The image was obtained with Artemis-2 VHFUS for ACA and ACD (Figure 1).

There are two types of ultrasonic techniques: contact and immersion. The ultrasound A-scan is a contact ultrasound technique that uses one thin, parallel sound beam, which is 

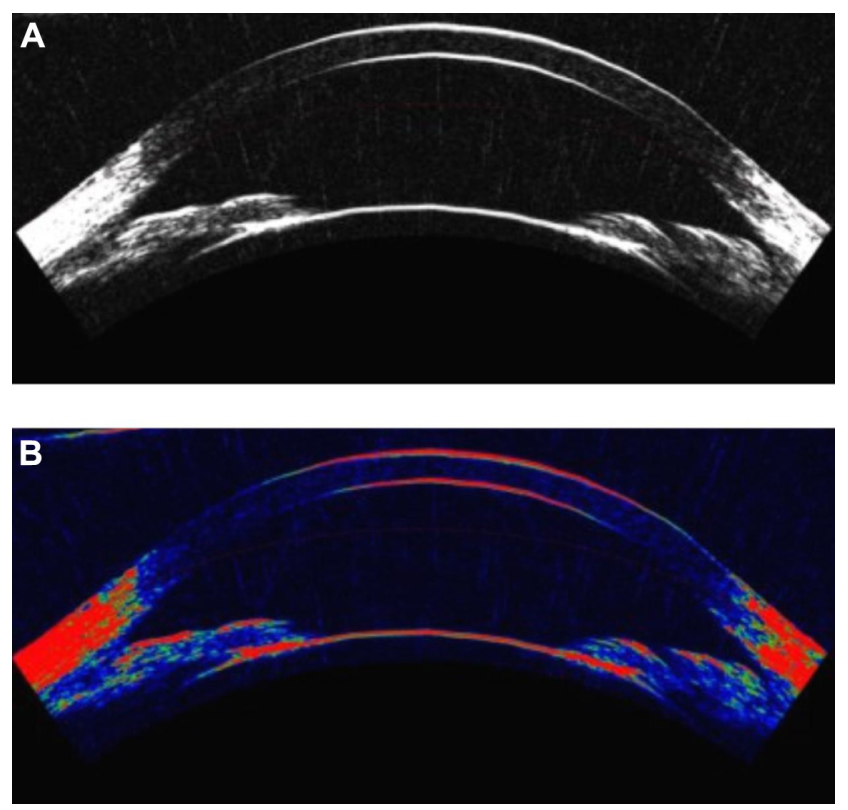

Figure I The image was obtained for one of the subjects with Artemis-2 VHFUS for ACA and ACD. A black and white, and $\mathbf{B}$ in color.

Abbreviations: VHFUS, very high frequency ultrasound scanner; ACA, anterior chamber angle; $A C D$, anterior chamber depth.

emitted from the probe tip at a frequency of approximately $10 \mathrm{MHz}$. The disadvantages associated with contact ultrasound are corneal indentation, relatively low resolution, and only moderate precision. ${ }^{28}$ The UBM is an immersion technique that uses a high-frequency $(50 \mathrm{MHz})$ ultrasound beam to measure various ocular parameters. The examiner must manually adjust the transducer head to maximize the centrality and perpendicularity of the images, which can be a time-consuming process. Analog-based UBM does not yield consistent images of the interface because analog processing does not produce a high enough signal-to-noise ratio between the interface echo complex and the surrounding tissue. ${ }^{11,14,15}$

Prior to use of the VuMAXTM UBM (Sonomed Inc, New Hyde Park, NY, USA), one drop of topical anesthesia ( $0.4 \%$ benoxinate hydrochloride) was instilled in the patient's eye. The cup was disinfected with an alcohol swab, and then filled with a $1 \%$ methylcellulose solution. The transducer head was immersed in this solution, and then the eye cup was placed on the sclera. The subject was then asked to look at a fixation target on the ceiling in order to maintain accommodation and fixation. The image was obtained with UBM for ACA and ACD (Figure 2).

\section{Statistical methods}

The demographic data for all subjects were analyzed using Microsoft Excel 2007 (Microsoft Corporation).
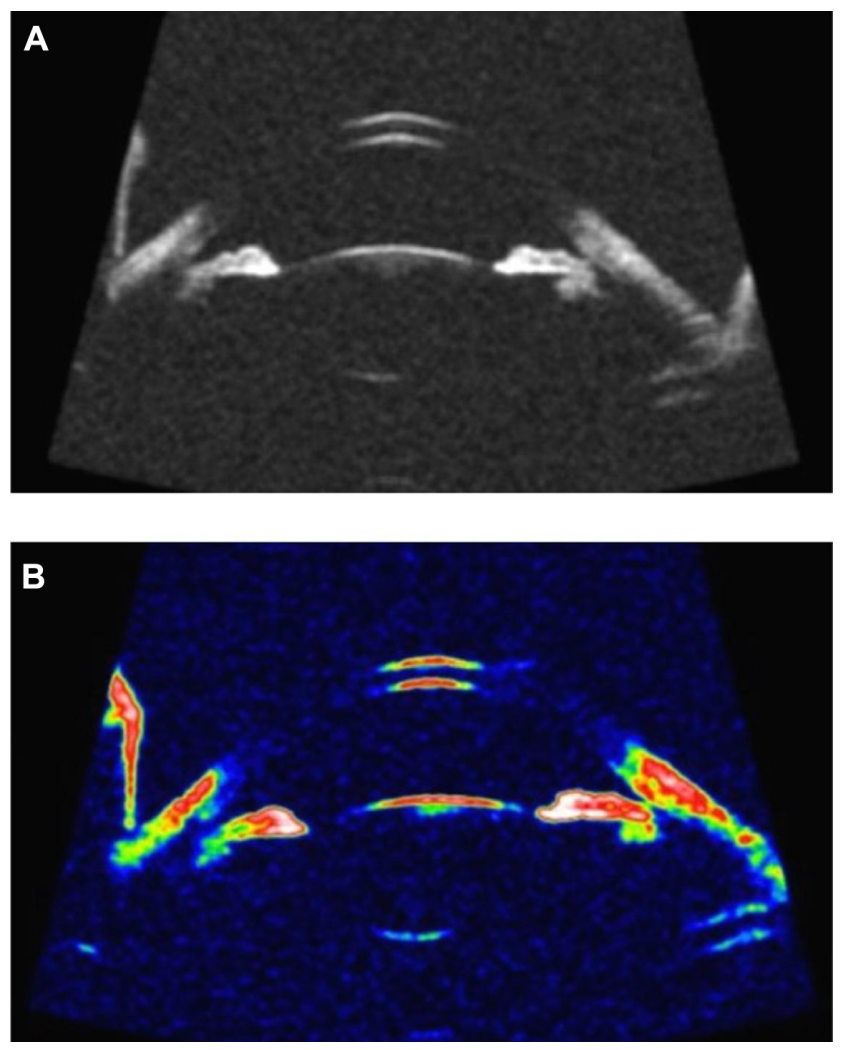

Figure 2 The image was obtained for the same subject but with UBM for ACA and ACD. A black and white, and $\mathbf{B}$ in color.

Abbreviations: UBM, ultrasound biomicroscopy; ACA, anterior chamber angle; $A C D$, anterior chamber depth.

The repeated-measures analysis of variance for ACA and ACD measurements was performed using InStat statistical software version 3.06 (GraphPad Software Inc, La Jolla, CA, USA). MedCalc software version 11.4.4.0 (MedCalc Software bvba, Mariakerke, Belgium) was used to test the Bland-Altman analysis to assess the limits of agreement between repeated measurements of the instruments, and an unpaired $t$-test was used to test the differences for statistical significance.

\section{Results}

The study included 59 normal subjects (32 right eyes, 27 left eyes). The mean ( \pm standard deviation) intraocular pressure was $14.00 \pm 1.50 \mathrm{mmHg}$. The mean refractive error (spherical equivalent) was $-0.50 \pm 1.00 \mathrm{D}$.

\section{Intraobserver repeatability of ACA and ACD measurements}

The intraobserver repeatability analysis of variance $P$-values for ACA and ACD measurements obtained using UBM and Artemis-2 VHFUS were 0.10 and 0.68 , and 0.68 and 0.09 , respectively. 


\section{Comparison of the ACA and ACD measurements}

The unpaired $t$-test for ACA and ACD measurements obtained using the UBM as compared to the Artemis-2 VHFUS were 8.41 and 1.51 , respectively. The unpaired $t$-test for the UBM and Artemis-2 VHFUS comparison revealed a statistically significant difference for the ACA measurements ( $P=0.0001)$ but not for the ACD measurements $(P=0.13)$. The mean difference percentage for ACD measurements was $3.1 \%$ for both measurements.

\section{Agreement between the instruments}

The mean differences, standard deviations, and limits of agreement for the ACA and ACD measurements obtained using the UBM versus the Artemis-2 VHFUS are summarized in Table 1. The Bland-Altman diagrams show the mean differences and agreement limits for the ACA and ACD measurements as obtained using the UBM versus the Artemis-2 VHFUS (Figures 3 and 4), respectively.

\section{Discussion}

Intraocular lens (IOL) implantation requires accurate measurements of ACD not only to determine IOL power and effective lens position, but also to prevent endothelial cell damage. ${ }^{28,29}$ Precise preoperative ACD measurement is needed to predict the exact postoperative IOL position. It has been reported that errors in the prediction of the effective lens position might account for $20 \%-40 \%$ of the inaccuracy in predicting total refractive error. ${ }^{30}$

Our results demonstrated good repeatability for the ACA and ACD measurements obtained using the UBM and the Artemis-2 VHFUS. The unpaired $t$-test revealed a significant difference between UBM and Artemis-2 VHFUS measurements of ACA $(P=0.0001)$, which suggests that the two instruments cannot be used interchangeably. In the case of ACD, this difference was not significant, which means that UBM and Artemis-2 VHFUS can be used interchangeably in young, healthy, oculovisually normal subjects. The Bland-Altman analysis of ACA measurements reveals a

Table I The mean $\pm S D$, mean differences $\pm S D$, and LOA of ACA and $A C D$ measurements with UBM and the Artemis-2 VHFUS

\begin{tabular}{lrrll}
\hline & \multicolumn{1}{l}{ UBM } & $\begin{array}{l}\text { Artemis-2 } \\
\text { VHFUS }\end{array}$ & $\begin{array}{l}\text { Mean } \\
\text { difference }\end{array}$ & LOA \\
\hline ACA (degree) & $41.83 \pm 5.03$ & $33.36 \pm 6.03$ & $8.50 \pm 2.50$ & $13.30 / 3.60$ \\
ACD (mm) & $2.96 \pm 0.34$ & $2.87 \pm 0.31$ & $0.09 \pm 0.27$ & $0.61 /-0.43$ \\
\hline
\end{tabular}

Abbreviations: SD, standard deviation; LOA, limits of agreement; ACA, anterior chamber angle; ACD, anterior chamber depth; UBM, ultrasound biomicroscopy; VHFUS, very high frequency ultrasound scanner.

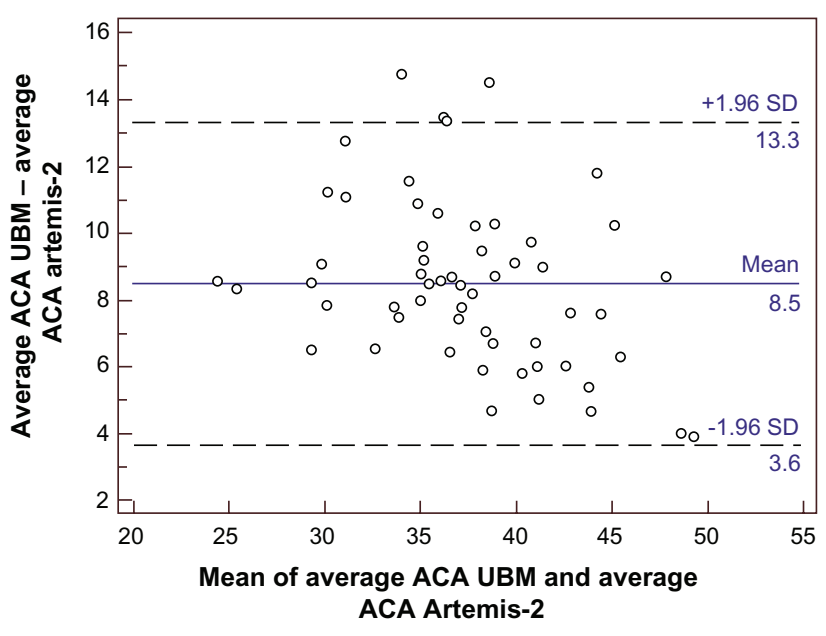

Figure 3 Bland-Altman diagram showing the difference and agreement limits of the ACA measurements obtained with UBM and the Artemis-2 VHFUS.

Abbreviations: ACA, anterior chamber angle; UBM, ultrasound biomicroscopy; VHFUS, very high frequency ultrasound scanner.

poor level of agreement between the UBM and the Artemis-2 VHFUS. The mean difference for the ACA measurements was $8.50^{\circ}$, which is higher than the threshold used for clinical acceptability. Bland-Altman analysis of the mean difference in UBM and Artemis-2 VHFUS ACD measurements revealed a high level of agreement. The mean difference was $0.09 \mathrm{~mm}$, which was insufficient to affect decisions related to refractive surgery in clinical practice. The mean difference percentage for ACD measurements was 3.1\%, which further indicates that UBM and Artemis-2 VHFUS ACD measurements are equally valid.

In studies assessing the precision and agreement of various techniques or instruments, the repeatability and

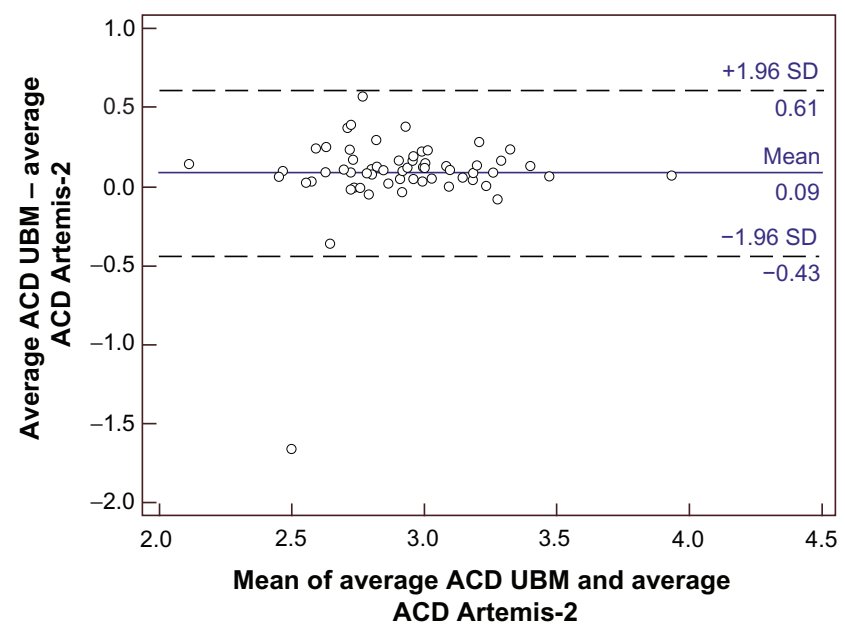

Figure 4 Bland-Altman diagram showing the difference and agreement limits of the ACD measurements obtained with the UBM and Artemis-2 VHFUS.

Abbreviations: $A C D$, anterior chamber depth; UBM, ultrasound biomicroscopy; VHFUS, very high frequency ultrasound; SD, standard deviation. 
reproducibility of each technique must be high. Several studies have reported that the intraobserver repeatability of UBM measurements with normal eyes was good for ACA, ${ }^{31-33}$ and excellent for ACD. ${ }^{14,31,34} \mathrm{We}$ found intraobserver repeatability to be high for both ACA and ACD UBM measurements. The same high level of intraobserver repeatability was observed for both ACA and ACD measurements obtained using the Artemis-2 VHFUS, as reported previously. ${ }^{16}$

Previous studies that investigated the accuracy of optical versus contact ultrasonic techniques for ACD measurement reported small differences $(<5 \%)$ with the use of optical techniques, but large differences $(10 \%-15 \%)$ for contact techniques. ${ }^{28,33}$ The difference percentage observed in this study $(3.1 \%)$ is similar to that reported previously for optical techniques. This might be because both instruments in this study utilized immersion ultrasound techniques that reduce mechanical applanation effects, while previous studies did not. The mechanical applanation involved in contact ultrasound is reported to reduce ACD estimates by $0.3 \mathrm{~mm} \cdot{ }^{14,35,36}$

Measurements of ACA opening distance (AOD) or anterior chamber volume (ACV) may also be used to characterize the ACA. Notably, both ACA and AOD measurements are reported to have high variability. ${ }^{33,34}$ The unpaired $t$-test revealed significant differences between UBM and Artemis-2 VHFUS ACA measurements. This could be due to human error in identifying the position of the scleral spur and the deepest point of the iris recess. The reproducibility of these measurements may also have suffered because of the inclusion of patients with irregular iris profiles among the study population. ${ }^{14,37}$

It is well documented that the ACD changes according to the accommodative status of the eye. ${ }^{38}$ Since there is no fixation system to block accommodation in UBM, underestimation of the ACD due to accommodation is expected. ${ }^{39}$ To overcome this limitation, the subject was instructed to fixate on a ceiling target to maintain accommodation. During the scan session, the examiner attempted to visually detect any instance of decentration and/or loss of fixation. ${ }^{40}$ The Artemis-2 VHFUS incorporates a fixation light and optical camera for visualization of the eye to ensure fixation. The unpaired $t$-test and Bland-Altman analyses reflect these differences.

Overall, our results were comparable with those from previous studies on normal subjects. For instance, Yazici et $\mathrm{al}^{27}$ reported mean ACD measurements of $2.94 \mathrm{~mm}$, $2.84 \mathrm{~mm}$, and $2.98 \mathrm{~mm}$ for the Visante OCT, Orbscan ${ }^{\circledR}$ II (Bausch and Lomb), and Pentacam, respectively. ${ }^{27}$ Our ACD measurements were $2.96 \mathrm{~mm}$ and $2.87 \mathrm{~mm}$ for the UBM and Artemis-2 VHFUS, respectively. Notably, ACD measurements obtained using the Visante OCT tend to be slightly higher than those obtained using the Artemis-2 VHFUS. ${ }^{11,16}$ Orbscan $^{\circledR}$ II ACD measurements are typically lower than those obtained using UBM or the Artemis-2 VHFUS; this could be because the Orbscan ${ }^{\circledR}$ II does not use a fixation point to block accommodation. ${ }^{39}$ Pentacam and UBM ACD measurements are similar. Artemis-2 VHFUS measurements are higher than corresponding values obtained using the Pentacam (Pentacam, Oculus Inc, Lynnwood, WA, USA), again owing to the lack of patient fixation. ${ }^{39}$ Piñero et al ${ }^{16}$ reported mean ACD mean values of $3.07 \mathrm{~mm}$ and $3.16 \mathrm{~mm}$ for the Artemis-2 VHFUS and Visante OCT, respectively. Our ACD values were slightly lower, possibly because of differences in the study population (eg, age, sample size) or to the fact that the Piñero et $\mathrm{al}^{16}$ study failed to consider refractive status, which was considered in the study presented here.

Rabsilber et $\mathrm{al}^{41}$ reported a mean ACA value of $36.28^{\circ}$ in normal subjects with the Pentacam. We found values of $41.83^{\circ}$ and $33.36^{\circ}$ using the UBM and the Artemis-2 VHFUS, respectively. It is possible to pinpoint the exact location of the angle being imaged with the Pentacam but not with the UBM. In a study of 20 normal eyes, Piñero et a ${ }^{16}$ reported a mean ACA of $37.40^{\circ}$ with use of the Artemis-2 VHFUS; that value is higher than the results reported here. This may be due to differences between the studies in terms of sample size, subject age, and attention to refractive error.

\section{Conclusion}

In case of the ACD, both instruments can be used interchangeably; however, with the ACA instruments cannot be used interchangeably.

\section{Acknowledgments}

We certify that we have participated sufficiently in the conception, design, and the interpretation of the data for this work, as well as in the writing of the manuscript, to take public responsibility for it. Neither this manuscript nor one with substantially similar content under our authorship has been published or is being considered for publication elsewhere.

\section{Disclosure}

The authors report no conflicts of interest in this work. We also certify that, where applicable, any affiliations with, or involvement in, any organization or entity with a direct financial interest in the subject matter or materials discussed 
in the manuscript (for example, employment, consultancies, stock ownership, honoraria, expert testimony) are disclosed in the paper.

\section{References}

1. Quigley HA, Broman AT. The number of people with glaucoma worldwide in 2010 and 2020. Br J Ophthalmol. 2006;90(3): 262-267.

2. Lowe RF. Aetiology of the anatomical basis for primary angle-closure glaucoma. Biometrical comparisons between normal eyes and eyes with primary angle-closure glaucoma. Br J Ophthalmol. 1970;54(3): 161-169.

3. Sihota R, Lakshimaiah NC, Agrawal HC, Pandey RM, Titiyal JS. Ocular parameters in the subgroups of angle closure glaucoma. Clin Experiment Ophthalmol. 2000;28(4):253-258.

4. Baikoff G, Lutun E, Ferraz C, Wei J. Static and dynamic analysis of the anterior segment with optical coherence tomography. J Cataract Refract Surg. 2004;30(9):1843-1850.

5. Radhakrishnan S, Goldsmith J, Huang D, et al. Comparison of optical coherence tomography and ultrasound biomicroscopy for detection of narrow anterior chamber angles. Arch Ophthalmol. 2005;123(8): 1053-1059.

6. Kalev-Landoy M, Day AC, Cordeiro MF, Migdal C. Optical coherence tomography in anterior segment imaging. Acta Ophthalmol Scand. 2007;85(4):427-430.

7. Leung CK, Cheung CY, Li H, et al. Dynamic analysis of dark-light changes of the anterior chamber angle with anterior segment OCT. Invest Ophthalmol Vis Sci. 2007;48(9):4116-4122.

8. Leung CK, Li H, Weinreb RN, et al. Anterior chamber angle measurement with anterior segment optical coherence tomography: a comparison between slit lamp OCT and Visante OCT. Invest Ophthalmol Vis Sci. 2008;49(8):3469-3474.

9. Alsbirk PH. Primary angle-closure glaucoma. Oculometry, epidemiology, and genetics in a high-risk population. Acta Ophthalmol Suppl. 1976;127:5-31.

10. Zhao JL. Anterior chamber depth measurement in the early diagnosis of primary angle closure glaucoma. Zhonghua Yan Ke Za Zhi. 1986;22(2):89-92. Chinese.

11. Dada T, Sihota R, Gadia R, Aggarwal A, Mandal S, Gupta V. Comparison of anterior segment optical coherence tomography and ultrasound biomicroscopy for assessment of the anterior segment. $J$ Cataract Refract Surg. 2007;33(5):837-840.

12. Dinc UA, Oncel B, Gorgun E, Yalvac IS. Assessment of anterior chamber angle using Visante OCT, slit-lamp OCT, and Pentacam. Eur J Ophthalmol. 2010;20(3):531-537.

13. Wang D, Pekmezci M, Basham RP, He M, Seider MI, Lin SC. Comparison of different modes in optical coherence tomography and ultrasound biomicroscopy in anterior chamber angle assessment. J Glaucoma. 2009;18(6):472-478.

14. Lee JY, Kim JH, Kim HM, Song JS. Comparison of anterior chamber depth measurement between Orbscan IIz and ultrasound biomicroscopy. J Refract Surg. 2007;23(5):487-491.

15. Ramani KK, Mani B, Ronnie G, Joseph R, Lingam V. Gender variation in ocular biometry and ultrasound biomicroscopy of primary angle closure suspects and normal eyes. J Glaucoma. 2007;16(1): 122-128.

16. Piñero DP, Plaza AB, Alió JL. Anterior segment biometry with 2 imaging technologies: very-high-frequency ultrasound scanning versus optical coherence tomography. J Cataract Refract Surg. 2008;34(1): 95-102.

17. Doors M, Berendschot T, de Brabander J, Webers CA, Nuijts RM. Value of optical coherence tomography for anterior segment surgery. J Cataract Refract Surg. 2010;36(7):1213-1229.

18. Dinc UA, Gorgun E, Oncel B, Yenerel MN, Alimgil L. Assessment of anterior chamber depth using Visante optical coherence tomography, slitlamp optical coherence tomography, IOL Master, Pentacam and Orbscan IIz. Ophthalmologica. 2010;224(6):341-346.
19. Reinstein DZ, Silverman RH, Archer T. Very high frequency digital ultrasound: Artemis 2 scanning in corneal refractive surgery. In: Vinciguerra P, Camesasca FI, editors. Refractive Surface Ablation: PRK, LASEK, Epi-LASIK, Custom, PTK, and Retreatment. Thorofare, NJ: SLACK Incorporated; 2006:315-330.

20. Wang RN, Zheng GY, Wang ST, et al. Quantitative observation on changes of anterior segment by ultrasound biomicroscopy after posterior chamber phakic intraocular lens implantation. Zhonghua Yan Ke Za Zhi. 2011;47(9):815-819. Chinese.

21. Sun JH, Sung KR, Yun SC, et al. Factors associated with anterior chamber narrowing with age: an optical coherence tomography study. Invest Ophthalmol Vis Sci. 2012;53(6):2607-2610.

22. Congdon NG, Foster PJ, Wamsley S, et al. Biometric gonioscopy and the effects of age, race, and sex on the anterior chamber angle. $\mathrm{Br} J$ Ophthalmol. 2002;86(1):18-22.

23. Xu L, Cao WF, Wang YX, Chen CX, Jonas JB. Anterior chamber depth and chamber angle and their associations with ocular and general parameters: the Beijing Eye Study. Am J Ophthalmol. 2008;145(5): 929-936.

24. Mapstone R, Clark CV. Diurnal variation in the dimensions of the anterior chamber. Arch Ophthalmol. 1985;103(10):1485-1486.

25. Read SA, Collins MJ, Iskander DR. Diurnal variation of axial length, intraocular pressure, and anterior eye biometrics. Invest Ophthalmol Vis Sci. 2008;49(7):2911-2918.

26. Ishikawa H, Inazumi K, Liebmann JM, Ritch R. Inadvertent corneal indentation can cause artifactitious widening of the iridocorneal angle on ultrasound biomicroscopy. Ophthalmic Surg Lasers. 2000;31(4): 342-345.

27. Yazici AT, Bozkurt E, Alagoz C, et al. Central corneal thickness, anterior chamber depth, and pupil diameter measurements using Visante OCT, Orbscan, and Pentacam. J Refract Surg. 2010;26(2):127-133.

28. Koranyi G, Lydahl E, Norrby S, Taube M. Anterior chamber depth measurement: a-scan versus optical methods. J Cataract Refract Surg. 2002;28(2):243-247.

29. Olsen T, Corydon L, Gimbel H. Intraocular lens power calculation with an improved anterior chamber depth prediction algorithm. J Cataract Refract Surg. 1995;21(3):313-319.

30. Olsen T. Sources of error in intraocular lens power calculation. J Cataract Refract Surg. 1992;18(2):125-129.

31. Urbak SF, Pedersen JK, Thorsen TT. Ultrasound biomicroscopy. II. Intraobserver and interobserver reproducibility of measurements. Acta Ophthalmol Scand. 1998;76(5):546-549.

32. Spaeth GL, Azuara-Blanco A, Araujo SV, Augsburger JJ. Intraobserver and interobserver agreement in evaluating the anterior chamber angle configuration by ultrasound biomicroscopy. J Glaucoma. 1997;6(1): $13-17$.

33. Tello C, Liebmann J, Potash SD, Cohen H, Ritch R. Measurement of ultrasound biomicroscopy images: intraobserver and interobserver reliability. Invest Ophthalmol Vis Sci. 1994;35(9):3549-3552.

34. Zhang Q, Jin W, Wang Q. Repeatability, reproducibility, and agreement of central anterior chamber depth measurements in pseudophakic and phakic eyes: optical coherence tomography versus ultrasound biomicroscopy. J Cataract Refract Surg. 2010;36(6):941-946.

35. Reddy AR, Pande MV, Finn P, El-Gogary H. Comparative estimation of anterior chamber depth by ultrasonography, Orbscan II, and IOLMaster. J Cataract Refract Surg. 2004;30(6):1268-1271.

36. Giers U, Epple C. Comparison of A-scan device accuracy. J Cataract Refract Surg. 1990;16(2):235-242.

37. Dawczynski J, Koenigsdoerffer E, Augsten R, Strobel J. Anterior optical coherence tomography: a non-contact technique for anterior chamber evaluation. Graefes Arch Clin Exp Ophthalmol. 2007;245(3): 423-425.

38. Koretz JF, Cook CA, Kaufman PL. Accommodation and presbyopia in the human eye. Changes in the anterior segment and crystalline lens with focus. Invest Ophthalmol Vis Sci. 1997;38(3):569-578.

39. Baikoff G, Lutun E, Ferraz C, Wei J. Static and dynamic analysis of the anterior segment with optical coherence tomography. $J$ Cataract Refract Surg. 2004;30(9):1843-1850. 
40. Li DJ, Wang NL, Chen S, Li SN, Mu DP, Wang T. Accuracy and repeatability of direct ciliary sulcus diameter measurements by full-scale 50-megahertz ultrasound biomicroscopy. Chin Med J. 2009;122(8): 955-959.
41. Rabsilber TM, Khoramnia R, Auffarth GU. Anterior chamber measurements using Pentacam rotating Scheimpflug camera. $J$ Cataract Refract. 2006;32(3):456-459.

\section{Publish your work in this journal}

Clinical Ophthalmology is an international, peer-reviewed journal covering all subspecialties within ophthalmology. Key topics include: Optometry; Visual science; Pharmacology and drug therapy in eye diseases; Basic Sciences; Primary and Secondary eye care; Patien Safety and Quality of Care Improvements. This journal is indexed on

Submit your manuscript here: http://www.dovepress.com/clinical-ophthalmology-journal

\section{Dovepress}

PubMed Central and CAS, and is the official journal of The Society of Clinical Ophthalmology (SCO). The manuscript management system is completely online and includes a very quick and fair peer-review system, which is all easy to use. Visit http://www.dovepress.com/ testimonials.php to read real quotes from published authors. 